\title{
Contraceptive practices among women seeking termination of pregnancy in one public hospital in Eastern Cape, South Africa
}

\begin{tabular}{|c|c|}
\hline \multicolumn{2}{|c|}{$\begin{array}{l}\text { Authors: } \\
\text { Ebenezer O. Oluwole }{ }^{1} \\
\text { Linda Skaal }^{1}\end{array}$} \\
\hline \multicolumn{2}{|c|}{$\begin{array}{l}\text { Affiliations: } \\
{ }^{1} \text { Department of Public } \\
\text { Health, University of } \\
\text { Limpopo, South Africa }\end{array}$} \\
\hline \multicolumn{2}{|c|}{$\begin{array}{l}\text { Research Project no.: } \\
\text { MREC/H/58/2013:PG }\end{array}$} \\
\hline \multicolumn{2}{|c|}{$\begin{array}{l}\text { Corresponding author: } \\
\text { Linda Skaal, } \\
\text { linda.skaal@ul.ac.za }\end{array}$} \\
\hline \multicolumn{2}{|c|}{$\begin{array}{l}\text { Dates: } \\
\text { Received: } 17 \text { Nov. } 2015 \\
\text { Accepted: } 30 \text { May } 2016 \\
\text { Published: } 31 \text { Aug. } 2016\end{array}$} \\
\hline \multicolumn{2}{|c|}{$\begin{array}{l}\text { How to cite this article: } \\
\text { Oluwole EO, Skaal L. } \\
\text { Contraceptive practices } \\
\text { among women seeking } \\
\text { termination of pregnancy in } \\
\text { one public hospital in Eastern } \\
\text { Cape, South Africa. Afr J Prm } \\
\text { Health Care Fam Med. } \\
\text { 2016;8(1), a1094. http:// } \\
\text { dx.doi.org/10.4102/phcfm. } \\
\text { v8i1.1094 }\end{array}$} \\
\hline \multicolumn{2}{|c|}{$\begin{array}{l}\text { Copyright: } \\
\text { @) 2016. The Authors. } \\
\text { Licensee: AOSIS. This w } \\
\text { is licensed under the } \\
\text { Creative Commons } \\
\text { Attribution License. }\end{array}$} \\
\hline \multicolumn{2}{|c|}{ Read online: } \\
\hline 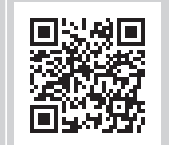 & $\begin{array}{l}\text { Scan this QR } \\
\text { code with your } \\
\text { smart phone or } \\
\text { mobile device } \\
\text { to read online. }\end{array}$ \\
\hline
\end{tabular}

Background: There is significantly high contraceptive knowledge in South Africa, but the uptake of contraceptives is average to low with resultant soaring of unplanned pregnancy and rising statistics of termination of pregnancy (TOP) services. This study aimed to establish the contraceptive practices among women in the South African population seeking TOP in one public hospital in Eastern Cape, South Africa.

Methods: A cross-sectional study was carried out among women seeking TOP in a women's clinic. Self-administered questionnaires were used as data collection tool, and the data collected were entered into SPSS software for analysis, using descriptive statistics to calculate frequencies and percentages while chi-square test was used to determine the associations between the socio-demography and contraceptive practices of the participants.

Results: Majority of the women were aged between 20 and 29 years, had secondary education, unemployed, single and resided in townships. Contraceptive uptake prior to termination of pregnancy (CTOP) among them was $44.1 \%$, but $85.8 \%$ had good contraceptives knowledge. Their contraceptive practices are determined by partner's opinion, source and availability of contraceptives, previous CTOP, side effect of contraceptives and having children. Age group, educational level and employment status were found to be related to the contraceptive practices of the participants but were not statistically significant.

Conclusion: To reduce unplanned pregnancies and subsequent number of women seeking CTOP, the socio-economic factors associated with contraceptive practices as well as the programmes, policies and guidelines of contraceptives need to be improved on for any improvement on the factors determining contraceptive practices.

\section{Background of the study}

The use of contraception to prevent pregnancy and its increased use among sexually active individuals can result in a significant reduction in unwanted pregnancies and resultant abortions. Globally, according to an estimation, 205 million pregnancies occur annually, with approximately 68 million of these pregnancies being unplanned pregnancies and 41 million of them ending in abortion. ${ }^{1}$ It is reported that over 200 million women prefer to delay their next pregnancy or not have children any more in developing countries, including South Africa (RSA); however, the majority of these women practice traditional and less-effective contraceptive methods or do not use any contraceptives. ${ }^{1}$

Many reasons account for poor uptake of contraceptives among women and they include lack of access, lack of awareness, cultural factors, religion, opposition to use by partners or family members, and fear of health risks and side effects of contraceptives. ${ }^{3}$ It is estimated that $90 \%$ of the abortion-related and $20 \%$ of the pregnancy-related morbidity and mortality can be prevented with the use of effective contraception. ${ }^{4}$ It is further reported that unintended pregnancy poses a major problem to reproductive health delivery in developing countries such as South Africa. Studies report that $35 \%$ of women become pregnant before the age of 20 years in South Africa and this has a significant impact because of economic, social, psychological and physical implications for those with unplanned pregnancies. ${ }^{5}$

Knowing the contraceptive practices of these women in the study will serve as pointer to where the service providers are failing and need refocusing and re-strategising. ${ }^{6}$

According to the findings of World Health Organization and Guttmacher Institute, ${ }^{6}$ it is reported that in low-income countries, where fertility rate is quite high, non-contraceptives usage contribute 
to two-thirds of unintended pregnancies and $11 \%$ of these lead to unsafe abortion which result in severe complications such as infections and bleeding. ${ }^{7}$ These unwanted pregnancies can be avoided by mere use of contraceptives. ${ }^{7}$

The South African Saving Mothers Report ${ }^{8}$ reports that maternal mortality rate increased from 152/100 000 live births in 2005-2007 to 176/100 000 live births in 2008-2010 in South Africa. Magadi and Curtis, ${ }^{9}$ found that wider range of contraceptive methods is directly proportional to higher contraceptive demand. Availability of a wider range of contraceptives has been found to give the women options to choose what is best for their contraceptive needs and thereby reduce chances of unplanned pregnancies that often result in termination of pregnancy (TOP). ${ }^{10}$

The use of contraceptives for prevention of unwanted pregnancy by women is one of the United Nations (UN) organisation's strategies in achieving Millennium Development Goal to improve maternal health. ${ }^{4}$ However, prevention of unwanted pregnancy requires quality reproductive health services so that women can access safe and efficient methods of contraception. ${ }^{4}$

The South African government has put in place various programmes, strategies and policies to facilitate the use of contraceptive services as a step to reducing fertility rates and increasing contraceptives uptake and therefore reducing poor maternal outcomes. However, a number of women seeking TOP at public hospitals in South Africa are rising. Therefore, understanding the characteristics of the women in this population, their contraceptive practices and the factors influencing contraceptive use may provide possible areas/ factors that could be targeted for interventions to prevent unplanned pregnancies, leading to subsequent reduction in termination of pregnancies. However, a number of women seeking TOP at public hospitals, such as in South Africa, are rising. ${ }^{11}$ The aim of this study was to establish the contraceptive practices among women seeking TOP in Dora Nginza Hospital, Port Elizabeth, Eastern Cape, South Africa.

\section{Research methodology Study design and approach}

The researchers used a descriptive cross-sectional design, quantitative study approach, targeting women aged 12-49 who were seeking TOP at the public hospital. Permission to conduct the study and ethical clearance were obtained from the Department of Health and Medunsa Research Ethics Committee, respectively.

\section{Sampling and sampling techniques}

Consecutive women attending the TOP clinic were approached to participate in the study and those who agreed to participate and met the inclusion criteria were included. A sample size of 339 was required based on an expected frequency of $50 \%$ with $95 \%$ confidence intervals having a width of $5 \%$. In order to compensate for possible attrition, a sample of 400 was intended. The clinic usually saw 15 patients a day for TOP and a total of around 2880 a year.

\section{Data collection tools}

Structured researcher-administered questionnaire, consisting of 29 questions, was used to collect data. The questionnaires were in three languages - English, Afrikaans and isiXhosa based on the languages of the target population. The questionnaire contained various questions relating to the demographic profile of the participants, contraceptive practices and factors influencing contraceptive practices.

A pretest was conducted through piloting to address reliability, and content validity was ensured by the use of experts in the clinic and the supervisor during the development of the questionnaire.

\section{Recruitment}

The researchers went to the women's clinic every morning, introduced the research and explained the purpose of the study to the potential participants in the presence of the two registered midwives who were trained on data collection. The prospective participants at that point in time were addressed in clear terms of potential benefits, risks, inconvenience and obligations associated with the research that might reasonably be expected to influence their willingness to participate. This was done at the waiting area of the clinic before their primary consultation with the midwives.

Those women who opted to participate were taken to another room and informed consent forms were given to them; after which they completed the questionnaire.

\section{Data analysis}

The data collected were entered into a Microsoft Excel spreadsheet, where it was edited and then imported into SPSS and EPI-INFO software for cleaning, management and analysis. Frequency distribution and descriptive statistics were used to summarise the socio-demographic variables, contraceptive practices and factors influencing contraceptive use which were expressed as means, standard deviation as well as median. Some of these data were also categorised, and percentages and proportions were calculated. Possible associations between independent variables such as the socio-demographic profile and the dependent variables such as the contraceptive practices as well as factors influencing the contraceptive practices of the women were determined using inferential analysis like cross-tabulation and chi-square test. Logic regression was utilised in determining the confidence intervals at $95 \%$ level of significance in order to predict feasible association among the variable at 0.05 level of significance and $p$-values less than 0.05 considered as statistically significant. 


\section{Results}

The results show that out of the 395 respondents, over half (55.4\%) were aged between 20 and 29 years, about one-third were $30-39$ years and $15.7 \%$ were less than 20 years of age. The majority $(84.6 \%)$ of the participants were black people, $14.7 \%$ were from mixed race people and less than $1 \%$ were white people. The majority of the respondents were single $(93.9 \%)$ and $72.7 \%$ were unemployed. About two-thirds (59.7\%) of all the participants have secondary education status, $32.2 \%$ had tertiary education and just less than $10 \%$ had primary education or less. Also, over two-thirds (76.5\%) of the participants reside in the township, $16.7 \%$ in the informal settlements and less than $7 \%$ in suburbs. Two-thirds (65.1\%) were unemployed and only one-third (34.9\%) were employed (Table 1).

The results show the majority of the respondents $(85.8 \%)$ reported that they knew about contraceptives, and $44.1 \%$ reported that they used contraceptives before pregnancy among the participants. One-third of the respondents reported that they heard about contraception from family $(30.4 \%) ; 25.8 \%$ heard from healthcare workers and only $3.3 \%$ did not know about contraceptives. Furthermore, 33.9\% of the respondents reported that they used condoms, $22.0 \%$ used injectable contraceptives and $32.7 \%(n=129)$ did not use any contraception before pregnancy. Eighty-seven percent $(87.4 \%)$ of the participants had no previous TOP while others had one or more. The results also show that a quarter (25.6\%) of the respondents believe TOP is a form of contraceptive (see Table 2).

The results further show that one-third of the women were aware of contraceptive problems; $42.5 \%$ were aware of contraceptive advantages/benefits. From the results, already having children was perceived to be the determinant of contraceptive use by two-thirds of the participants, while number of children, contraceptive side effects, availability

TABLE 1: Demographic profile of the participants.

\begin{tabular}{llcc}
\hline Variables & $(\boldsymbol{n}=\mathbf{3 9 5})$ & Frequencies $(\boldsymbol{n})$ & Percentages (\%) \\
\hline Age group & $<20$ years & 62 & 15.7 \\
& 20-29 years & 219 & 55.4 \\
& 30-39 years & 114 & 28.9 \\
Race & Black people & 334 & 84.6 \\
& Mixed race people & 58 & 14.7 \\
& White people & 3 & 0.8 \\
Educational & Primary or less & 32 & 8.1 \\
status & Secondary & 236 & 59.7 \\
& Tertiary & 127 & 32.2 \\
Religion & Christians & 378 & 95.7 \\
& Muslim/Hindu & 6 & 1.5 \\
& Others & 11 & 2.8 \\
Marital & Single & 371 & 93.9 \\
status & Married & 24 & 6.1 \\
Residence & Township & 302 & 76.5 \\
& Informal settlement & 66 & 16.7 \\
& Suburb & 27 & 7.8 \\
Employment & Employed & - & 34.9 \\
status & Unemployed & - & 65.1 \\
\hline Source: $A u t t$ & & & \\
\hline
\end{tabular}

Source: Authors' own work and source of contraceptives were perceived to determine use $(42.8 \% ; 43.8 ; 39.5 \% ; 49.4 \%$, respectively). The most commonly reported factor influencing contraceptive practices is the source of contraceptive $(49.4 \%)$ and least reported factor is judgement by others (22.0\%). Also, 31.4\% of the respondents reported that partner's opinion about contraceptive use affected contraceptive practices. Also, 40\% of the participants reported that previous TOP determined contraceptive use and a quarter $(25.6 \%)$ viewed TOP as a form of contraceptive. From the results, staff attitude (35.9\%), partner's opinion $(31.4 \%)$, judgement by others $(22.0 \%)$ and religious belief $(26.3 \%)$ were perceived to determine contraceptive use by participants (see Table 3).

The results also show that two-thirds of the women at $<20$ years, those at 29-30 years and 30-39 years reported that they were not using contraceptives prior to getting pregnant $(66.1 \%, 53 \%$ and $56.1 \%$, respectively) though not statistically significant $\left(\chi^{2}=3.398 ; p=0.183\right)$ (see Table 4).

\section{Discussion}

The results of this study revealed that there is still an alarming number of black women seeking TOP in Eastern Cape, South Africa. Of the population size of 1880 women seeking TOP, a purposive sampling was used to select 395 women, majority of whom were black people. Several studies have reported similar race distribution when it comes to TOP, where black people remained the majority race seeking TOP compared to other races in most parts of South Africa. ${ }^{10,12,13}$ Of interest, this study found that most women between 20 and 29 years requested TOP more than any other age groups. At this age, it is assumed that women understand the risks of engaging in unprotected sexual

TABLE 2: Contraceptive practices of the participants.

\begin{tabular}{|c|c|c|c|}
\hline Variables & $(n=395)$ & Frequency & Percentages (\%) \\
\hline \multirow{2}{*}{$\begin{array}{l}\text { Contraceptive } \\
\text { knowledge }\end{array}$} & Yes & 339 & 85.8 \\
\hline & No & 56 & 14.2 \\
\hline \multirow{2}{*}{$\begin{array}{l}\text { Knowledge of hospital as } \\
\text { source of contraceptives }\end{array}$} & Yes & 297 & 75.2 \\
\hline & No & 98 & 24.8 \\
\hline \multirow{2}{*}{$\begin{array}{l}\text { Use of contraception } \\
\text { before pregnancy }\end{array}$} & Yes & 174 & 44.1 \\
\hline & No & 221 & 55.9 \\
\hline \multirow{6}{*}{$\begin{array}{l}\text { Source of information } \\
\text { about contraceptives }\end{array}$} & Family & 120 & 30.4 \\
\hline & Friends & 69 & 17.5 \\
\hline & Healthcare workers & 102 & 25.8 \\
\hline & Media & 81 & 20.5 \\
\hline & Partner & 10 & 2.5 \\
\hline & Not sure & 13 & 3.3 \\
\hline \multirow{5}{*}{$\begin{array}{l}\text { Types of contraceptives } \\
\text { used before pregnancy }\end{array}$} & None & 128 & 32.6 \\
\hline & Injectable & 87 & 22.0 \\
\hline & Oral & 34 & 8.6 \\
\hline & Condoms & 134 & 33.9 \\
\hline & Mixed & 11 & 2.8 \\
\hline \multirow[t]{4}{*}{ Previous TOP } & None & 345 & 87.4 \\
\hline & 1 & 38 & 9.6 \\
\hline & 2 & 10 & 2.5 \\
\hline & 3 & 2 & 0.5 \\
\hline \multirow{2}{*}{$\begin{array}{l}\text { Use TOP as } \\
\text { contraceptive }\end{array}$} & Yes & 101 & 25.6 \\
\hline & No & 295 & 74.4 \\
\hline
\end{tabular}

Source: Authors' own work 
TABLE 3: Self-reported factors influencing contraceptives practices.

\begin{tabular}{lcc}
\hline Factors & Yes $N(\%)$ & No $N(\%)$ \\
\hline Awareness of contraceptives & $137(34.7)$ & $258(65.3)$ \\
Awareness of contraceptive problems & $168(42.5)$ & $227(57.5)$ \\
Awareness of contraceptives advantages & & \\
Determinants of contraceptive use & $265(67.1)$ & $130(32.9)$ \\
Already having other children & $169(42.8)$ & $226(57.2)$ \\
Number of children determine contraceptive use & $173(43.8)$ & $222(56.2)$ \\
Side effect of contraceptive influence use & $156(39.5)$ & $239(60.5)$ \\
Contraceptive availability determine use & $195(49.4)$ & $200(50.6)$ \\
Source of contraceptive determine use & & \\
History of TOP & $158(40.0)$ & $237(60.0)$ \\
Previous TOP determine contraceptive use & $101(25.6)$ & $294(74.4)$ \\
TOP as form of contraceptive & & \\
Perceived attitude & $142(35.9)$ & $253(64.1)$ \\
Staff attitude determine contraceptive use & $124(31.4)$ & $271(68.6)$ \\
Partner opinion determine contraceptive use & $87(22.0)$ & $308(78.0)$ \\
Judgement by others determine contraceptive use & $104(26.3)$ & $291(73.7)$ \\
\hline Religious believe determine contraceptive use &
\end{tabular}

Source: Authors' own work

TOP, termination of pregnancy.

TABLE 4: Cross-tabulation between age group and pre-pregnancy contraceptive use.

\begin{tabular}{llccc}
\hline Variables & & \multicolumn{2}{c}{$\begin{array}{c}\text { Pre-pregnancy } \\
\text { contraceptive use }\end{array}$} & \multirow{2}{*}{$\boldsymbol{P \dagger}$} \\
\cline { 3 - 4 } & & Yes $N(\%)$ & No $N(\%)$ & \\
\hline Age group & $<20$ years $(N=62)$ & $21(33.9)$ & $41(66.1)$ & \\
& $20-29$ years $(N=219)$ & $103(47.0)$ & $116(53.0)$ & \multirow{2}{*}{0.183} \\
& $30-39$ years $(N=114)$ & $50(43.9)$ & $64(56.1)$ & \\
\hline
\end{tabular}

Source: Authors' own work

$\dagger$, Chi-square: $\chi=3.398$.

activity or without contraceptive use, compared with adolescents. Of concern is that this is the era where HIV rates are escalating in South Africa; therefore, we need to focus on this group of young adults to raise awareness of the dangers of such behaviours. Currently, statistics report that more than $30 \%$ of women between 20 and 34 years were infected with HIV in this country ${ }^{14}$; it is therefore of concern that these women continue to engage in risky sexual behaviours, despite the fact that they are at high risk of contracting HIV.

Furthermore, this study found that only a quarter of the women seeking TOP were using contraceptives before they got pregnant. Contraceptive uptake is reported to be at $65 \%$ nationally, according to the South Africa Demographic Health Survey. ${ }^{15}$ Even in this study, contraceptive use prior to pregnancy was found to be low. Of concern is that some of women reported that they used condoms prior to pregnancy, however, incorrect and inconsistent use of any form of contraceptives have resulted in unplanned/unwanted pregnancies that led to these women seeking TOP in our study. Interestingly, we found that over half of the women reported that they were not using contraception before pregnancy, this, despite the fact that the majority of these participants had excellent-to-good contraceptive knowledge. Women with good knowledge about contraceptive use are expected to be more assertive and grounded in knowing which risks exist when one engages in unprotected sexual activity such as unwanted pregnancy, which could have been prevented by mere use of contraceptives that are free of charge in South Africa.

For those women who reported that they were using contraceptives prior to pregnancy, we found that they used a wide range of sources to seek contraceptive information such as families and healthcare workers, while a few relied on media and friends. These results show that families are beginning to show more interest regarding reproductive health than previously reported by Aderibigbe and Basebang. ${ }^{15}$ Also, unlike in other studies ${ }^{16,17,18}$ where media was found to be the major source of information on contraceptives, this study found only $20 \%$ of the respondents reported media to be their source of information on contraception. The disadvantages of media as a source of contraceptive information is that information could be easily misinterpreted, as it is brief and does not allow audience to seek clarity, contributing to risk of poor understanding of contraceptive use and resultant unwanted pregnancies if information is misinterpreted.

The significantly lower usage of contraception and comparably high contraceptive knowledge by the participants in this study is a concern because it shows that knowledge does not always translate to behaviour change in this group of women. This has also been found by several studies across Africa ${ }^{19,20,21,22}$ that reported that the low contraceptive use is directly related to poverty and illiteracy. In addition, up to half of women reported that availability and source of contraceptives were the determinants influencing the use of contraceptives. There is a necessity to promote contraceptive usage among these women within community settings in order to secure a much higher contraceptives uptake as recommended by the National Contraception Guidelines. This further indicates the need for continuous creation of awareness through various means about the available contraceptive services at the other sources. Additionally, the campaigns to be done should include increased outlets where contraceptives can be accessed, such as reinforcing accessibility within community settings.

Another significant finding in this study is that a quarter of the women viewed TOP as a form of contraceptive, implying that they are likely to terminate pregnancy in future. Already in this study, about $3 \%$ of women reported that they had had more than one TOP, all of which viewed TOP as a form of contraception, as found in similar studies in South Africa..$^{23,24,25}$

\section{Limitations}

The participants were chosen from the women seeking termination of pregnancies at the women's clinic of Dora Nginza Hospital at the time of the study. Probably including women coming for other services at the hospital will give more information about availability, sources, access and other factors influencing the contraceptives practices.

In addition, the research was conducted in a health institution thereby revealing details of only the women seeking such 
services and may be different from the overall community. However, the study showed the participants were from widespread areas of the community including informal settlement, township and suburban areas.

Furthermore, the study was cross-sectional and therefore only revealed the contraceptive practices of the participants prior to pregnancy and not the changes over a period of time. A prospective study over a period of time is recommended to provide pattern of contraceptive practice over time in the community.

\section{Strengths}

The most important strength of this study is the fact that it highlights the contraceptive practices of women who seek TOP in public hospitals. This information can be used to design intervention programmes specifically for women who seek TOP, in order for them to adopt a new behaviour of preventing unwanted pregnancy. Therefore, it adds to the existing body of knowledge and helps to fill the literature on contraceptive practices among women seeking TOP in South Africa.

\section{Recommendations}

We feel that there is a need to include men in contraceptive programmes in order to improve joint family/partner collective decision-making when it comes to contraceptive use. We suggest that government must increase awareness in order to improve and encourage more contraceptives uptake among the women.

\section{Conclusion}

This study provided us with relevant details on the contraceptive practices of women in terms of their sociodemographics, various practices involved with, as well as associations between their socio-demographic data and contraceptive practices. The study revealed that the contraceptive uptake was low prior to TOP, despite having a very high level of contraceptive knowledge and high level of education among the women seeking TOP in Port Elizabeth, South Africa. Knowledge of contraceptives in terms of side effects, sources and availability significantly determine contraceptive practices among the women seeking TOP in a hospital. Lastly, from the study it can be suggested that partner's/spouse's opinion is likely to play a significant role in the women' decision on contraceptive usage, if incorporated in decision-making process of which contraceptive to use.

\section{Acknowledgements}

We would like to thank Professor Supa Pengpid who assisted in the early stages of this research. The study was funded by the Directorate General for Development Cooperation (DGDC) through the Flemish Interuniversity Council (VLIRUOS). Many thanks to the (VLIR-UOS) for all the financial support.

\section{Competing interests}

The authors declare that they have no financial or personal relationships which may have inappropriately influenced them in writing this article.

\section{Authors' contributions}

At the time when this study was conducted, E.O.O. was a student pursuing Master of Public Health, under the supervision of L.S. E.O.O. was responsible for data collection, capturing and was the project leader, and contributed to $50 \%$ of this article. L.S. supervised data collection, cleaned and analysed data; conceptualised the article and reanalysed data for the purpose of publishing; and contributed to $50 \%$ of this article production.

\section{References}

1. WHO, PRB. The world population data sheet [homepage on the Internet]. Washington, DC: Population Reference Bureau; 2011 [cited 2013 Oct 15]. Available form: http://www.prb.org/publications/datasheets/2011/world-population-datasheet.aspx

2. Singh $S$, Darroch $E$, Vlassoff $M$, Nadeau J. Adding it up: The benefits of investing in sexual and reproductive health [homepage on the Internet]. New York: The Alan Guttmacher Institute; 2003 [cited 2012 Aug 4]. Available from: http://www. guttmacher.org/sections/contraception. php? scope $=$ comparative $\% 20$ international

3. Carr $\mathrm{D}$, Khan $\mathrm{M}$. The unfinished agenda: Meeting the needs for family planning in less developed countries [homepage on the Internet]. Washington, DC: Population Reference Bureau; 2004 [cited 2012 Aug 2]. Available from: http://www.prb.org/ Publications/Datasheets/2012/world-population-data-sheet.aspx

4. Williamson L, Parkes A, Wight D, Petticrew M, Hart G. Limits to modern contraceptive use among young women in developing countries: A systematic review of qualitative research. Reprod Health. 2009;6(3):1-12. http://dx.doi. org/10.1186/1742-4755-6-3

5. Wood K, Jewkes R. Blood blockages and scolding nurses: Barriers to adolescent contraceptive use in South Africa. Reprod Health Matters. 2006;14(27):109-118. http://dx.doi.org/10.1016/S0968-8080(06)27231-8

6. Maternal Mortality Update. 2002 [cited 2013 Oct 17]. Available from: http:// www.unfpa.org/sites/default/files/pub-pdf/mmupdate-2002_eng.pdf

7. WHO, Gutmacher Institute. Facts on induced abortion worldwide. 2007 [cited 2013 Oct 17]. Available from: www.searo.who.int/LinkFiles/Publications_Facts on_Induced_Abortion_Worldwide.pdf

8. Saving Mothers Fifth Report of 2008 to 2010, Fifth report on South Africa Department of Health [homepage on the Internet]. 2012 [cited 2012 Dec 11] Available from: www.doh.gov.za/docs/reports/2012/savingmothersshort.pdf

9. Magadi M, Curtis L. Trends and determinants of contraceptive method choice in Kenya. Stud Fam Plann. 2003;34(3):149-159. http://dx.doi.org/10.1111/j.17284465.2003.00149.x

10. Adinma E, Ifeanyi J, Brian A, et al. Awareness and use of contraception by women seeking termination of pregnancy in south eastern Nigeria. Asian Pac J Trop Dis. 2011;1(1):71-75. http://dx.doi.org/10.1016/S2222-1808(11)60018-2

11. Health System Trust. Health statistics: TOPs (terminations of pregnancy), Health Systems Trust [homepage on the Internet]. [cited 2012 Sept 12]. Available from: www.indicators.hst.org.za/healthstats/47/data

12. Maja T, Ehlers V, King L. Contraceptives practices in Northern Tshwane, Gauteng Province. Afr J Online. 2002 [cited 2014 Feb 2];9:4. Available from: http://www. ajol.info/index.php/hsa/article/view/10296

13. Lang $F$, Joubert $G$, Prinsloo $E$. Is pregnancy termination being used as a family planning method in Free State? S Afr Fam Pract J. 2005;47(5):52-55. http://dx.doi. org/10.1080/20786204.2005.10873232

14. Macleod C, Tracey T. A decade later: Follow-up review of South African research on the consequences of and contributory factors in teen-aged pregnancy. S Afr Psychol. 2010;40(1):18-31. http://dx.doi.org/10.1177/008124631004000103

15. UNAIDS. UNAIDS report on global AIDS epidemics. The 2012 revision [homepage on the Internet] [cited 2013 Sept 12]. Available from: http://www.unaids.org/ sites/default/files/en/media/unaids/contentassets/documents/ epidemiology/2012/gr2012/20121120_UNAIDS_Global_Report_2012_with_ annexes_en.pdf

16. South Africa Demographic and Health Survey (SADHS). Contraception and fertility preferences: Unwanted and wanted fertility [homepage on the Internet]. 2003 [cited 2013 Jun 6]. Available from: http://www.doh.gov.za/facts/sadhs-f. html

17. Aderibigbe $M$, Basebang $M$. Contraceptive awareness among adolescents in Lagos, Nigeria. Bachelor's Thesis; 2011 [cited 2014 Feb 8]. Available from: http:// www.theseus.fi/bitstream/handle/10024/32673/Basebang_Aderibigbe. pdf?sequence $=1$ 
18. Onwasigwe $\mathrm{C}$. Contraceptives knowledge and practice among married women in Enugu metropolis. Orient J Med. 2001;13(13):67.

19. Bassey E, Abassattai A, Asuquo E, Udoma J, Oyo-ita A. Awareness, attitude and practice of contraception among secondary school girls in Calabar. Niger J Med. 2005;14(2):146-150.

20. Oye-Adeniran B, Adewole F, Umoh A, Ekanem E, Gbadegesin A, Iwere N Community-based survey of unwanted pregnancy in South-Western Nigeria. Afr Reprod Health. 2004;8(3):103-115. http://dx.doi.org/10.2307/3583397

21. Abiodun A, Balogun BC. Sexual activity and contraceptive use among young female students of tertiary educational institutions in llorin, Nigeria. J Contracept. 2008;79(2):146-149. http://dx.doi.org/10.1016/j.contraception.2008.08.002
22. Bibi S, Memon A, Memon Z. Contraceptive knowledge and practices in two districts of Sindh Pakistan - A hospital based survey. J Pak Med Assoc. 2008;58:254-257.

23. Khan T, Khan R. Fertility behaviour of women and their house hold characteristics - A case study of Punjab Pakistan. J Hum Ecol. 2010;30:11-17.

24. De Jonge, Jewkes R, Levin J. Randomised controlled trial of the efficacy of misoprostol used as a cervical ripening agent prior to termination of pregnancy in the first trimester. S Afr Med J. 2000;90(3):256-262.

25. Ramonate N, Hiemstrar L, De Coning E. Bio-social profile and survey of women seeking termination of pregnancy at Pelonomi and National Hospitals, Bloemfontein. S Afr Med J. 2001;91:500-501. 